EDITORIAL

\section{Reviewers 2017}

The editors and staff of IJIC would like to thank those individuals who served as peer reviewers for manuscripts submitted in 2017.

\author{
Angel Asensio \\ Natalie Bruce \\ Ana Budimir \\ Mireia Cantero Caballero \\ Carlos Magno Castelo Branco Fortaleza \\ Candace Friedman \\ Marjory Greig \\ Jo Henman \\ Smilja Kalenic \\ Donna Moralejo \\ Elena Munez \\ Undine Nash \\ Maria Clara Padoveze \\ Walter Popp \\ Ulrika Ransjo \\ Judith Richards \\ Birgit Ross \\ Viviana Rodriguez \\ Glenda Schuh \\ Akeau Unahalekhaka
}

